\title{
Perencanaan Arena Gokar dan RC Cars Indoor di Pulau Kumala Tenggarong Penekanan Pada Utilitas
}

\author{
Mafazah Noviana,,${ }^{*}$ Cisyulia Octavia, ${ }^{2}$ Rahmat Dwi Saputra ${ }^{3}$ \\ ${ }^{1,2,3}$ Program Studi Arsitektur, Jurusan Desain, Politeknik Negeri Samarinda, Samarinda, Indonesia
}

\begin{abstract}
Lots of entertainment and game facilities that are no longer active on Kumala Tenggarong Island have caused a decline in the number of visitors each year, one of the facilities is outdoor Gokart Arena which currently in poor condition. The solution to increase visitor attraction and reintroduce Karting to the public is by planning Gokart Arena and RC Cars Indoor Arena as entertainment and game-themed racing facilities on Kumala Tenggarong Island. However Gokart racing activities have a negative impact on the environment such as residual liquid (oil) and solid waste (iron frame, etc.), cause noise and pollution and require good lighting for the safety of racers, therefore building design is emphasized on utilities, especially wastewater, natural lighting and natural ventilation for sustainability and comfort of buildings and the environment can be maintained properly. The application of the industrialist architectural style to the facade and interior layout through material exposure elements creates a unique character in the building with a rough and masculine look.
\end{abstract}

Keywords: Kumala Island, Gokart, RC Cars, Utilities, Industrial

\begin{abstract}
Abstrak
Banyaknya fasilitas hiburan dan permainan yang sudah tidak aktif di Pulau Kumala Tenggarong menyebabkan menurun-nya jumlah pengunjung setiap tahun-nya, salah satunya yaitu Arena permainan Gokar outdoor yang saat ini kondisinya tidak terawat. Solusi untuk meningkatkan kembali daya tarik pengunjung serta memperkenalkan kembali olahraga Karting kepada masyarakat umum yaitu dengan membuat Arena Gokar dan Arena RC Cars Indoor sebagai fasilitas hiburan dan permainan yang bertema-kan olahraga balapan di Pulau Kumala Tenggarong. Namun Aktifitas balapan Gokar memiliki dampak negatif terhadap lingkungan seperti sisa limbah cair (oli) maupun padat (rangka besi, dll), menimbulkan bising dan polusi serta membutuhkan pencahayaan yang baik demi keselamatan pembalap, untuk itu perancangan bangunan ditekankan pada utilitas khususnya air limbah, pencahayaan alami dan penghawaan alami agar keberlangsungan dan kenyamanan bangunan maupun lingkungan dapat terjaga dengan baik. Penerapan gaya arsitektur industrial pada fasad dan tata ruang dalam melalui elemen material ekspos yang menciptakan karakter unik pada bangunan dengan tampilan rough dan maskulin.
\end{abstract}

Kata Kunci : Pulau Kumala, Gokar, RC Cars, Utillitas, Industrial

\section{Pendahuluan}

Pulau Kumala Tenggarong yang terletak di Kecamatan Tenggarong, Kabupaten Kutai Kartanegara merupakan salah satu objek wisata terpopuler yang ramai dikunjungi oleh wisatawan luar kota seperti Samarinda dan Balikpapan. Pulau seluas 76 hektar ini memiliki fasilitas hiburan dan permainan seperti sky tower, kereta gantung, komedi putar, arena Gokar, pasar seni dan wisata kuliner. Namun seiring berjalannya waktu perkembangan dan fasilitas Pulau Kumala Tenggarong tidak memiliki kualitas yang baik, beberapa fasilitas sudah tidak beroperasi lagi seperti sky tower, komedi putar dan Gokar.

Berdasarkan hasil pengamatan penulis, fasilitas Gokar outdoor di Pulau Kumala Tenggarong yang berada di cluster service \& umum kondisinya memang memprihatinkan dan tidak terawat, mobil-mobil kart sudah tidak

\footnotetext{
*Corresponding author : mafazah79@gmail.com
} 
ada lagi, pembatas lintasan yang rusak serta sampah-sampah bertebaran didalam wahana tersebut. Sehingga dirasa perlu untuk membuat sebuah Perencanaan arena Gokar indoor di Pulau Kumala Tenggarong dengan perbedaan dari aspek lintasan/arena yang berada di dalam ruangan (indoor) dan akan dibangun di cluster hiburan \& permainan, serta menambahkan fasilitas arena balap RC Cars Indoor.

Dengan latar belakang yang telah dijelaskan mengapa Arena Gokar dan RC Cars Indoor perlu direncanakan, maka rumusan masalah yang timbul yaitu :

1) Bagaimana mendesain arena Gokar dan RC Cars indoor di Pulau Kumala Tenggarong dengan penekanan pada utilitas.

2) Bagaimana mendesain arena Gokar dan RC Cars indoor dengan gaya arsitektur Industrial pada tata ruang dalam.Sedangkan artikel yang berbentuk resensi buku, biografi, atau feature yang berasal dari pemikiranpemikiran kritis, dapat disesuaikan dalam hal pengaturan sub-judulnya. Anda diharapkan selalu mengontrol format tulisan anda pada menu paragraph.

\section{Kerangka Teori}

Gokar merupakan salah satu jenis kendaraan roda empat dengan atap terbuka sederhana dan kecil yang digunakan untuk olahraga. Gokar biasanya dilakukan di lintasan/sirkuit dengan skala kecil. Balapan Gokar biasanya dianggap sebagai dasar sebelum menuju olahraga motor yang lebih mahal dan lebih tinggi [1].

Kart racing biasanya digunakan sebagai biaya rendah dan relatif aman untuk memperkenalkan driver untuk motor racing. Banyak orang mengasosiasikan itu dengan pembalap muda, tetapi orang dewasa juga sangat aktif di Karting. Karting dianggap sebagai langkah pertama dalam karier pembalap serius.

\subsection{Jenis Gokar:}

a. Gokar Listrik:

Berbiaya pemeliharaan rendah, hanya membutuhkan baterai timbal-asam dari mobil yang dipasang setelah diisi dayanya. Karena mesin jenis ini bebas polusi dan tidak mengeluarkan asap, sirkuitnya dapat diletakkan dalam ruangan tertutup.

b. Gokar 2-langkah:

Dibangun oleh produsen yang khusus memproduksi mesin jenis ini yaitu Comer, IAME (Parilla, Kmet), TM, Vortex, Titan, REFO, Yamaha dan Rotax. mesin ini berdaya sekitar 8 tenaga kuda untuk mesin satu silinder 60cc (MiniROK buatan Vortex), pada mesin 250cc dapat menghasilkan 80 tenaga kuda dua silinder [2].

c. Gokar 4-langkah:

Berpendingin udara berbasis mesin standar industri, kadang-kadang dengan sedikit modifikasi, berdaya dari sekitar 5-20 hp. Mesin jenis ini diproduksi oleh Briggs \& Stratton, Techumseh, Kohler, Robin dan Honda ada juga mesin 4-langkah lebih kuat, berdaya dari 15 tk hingga 48 tk dan mampu mencapai putaran mesin sekitar 11.000 Rpm [2].

\subsection{Jenis Trek Gokar}

Terdapat beberapa jenis trek Gokar, berikut ini adalah keuntungan dan kerugian tiap jenis trek Gokar,

Tabel 1. Jenis Trek Gokar

\begin{tabular}{|c|c|c|}
\hline OUTDOOR & INDOOR & OUTDOOR \& INDOOR \\
\hline $\begin{array}{l}\text { Lantai yang digunakan adalah } \\
\text { menggunakan beton atau aspal }\end{array}$ & $\begin{array}{l}\text { Lantai yang digunakan adalah } \\
\text { menggunakan beton atau aspal }\end{array}$ & $\begin{array}{l}\text { Lantai yang digunakan adalah } \\
\text { menggunakan beton atau aspal }\end{array}$ \\
\hline $\begin{array}{l}\text { Rata-rata Panjang sirkuit mulai } \\
\text { dari } 500-1.000 \mathrm{~m}\end{array}$ & $\begin{array}{l}\text { Rata-rata Panjang sirkuit mulai } \\
\text { dari 250-600m }\end{array}$ & \multirow{3}{*}{$\begin{array}{l}\text { Disesuaikan dengan luas dan } \\
\text { bentuk site }\end{array}$} \\
\hline $\begin{array}{l}\text { Rata-rata luas arena 5.000- } \\
15.000 \mathrm{~m}\end{array}$ & Rata-rata luas arena $2.500-6.000 \mathrm{~m}$ & \\
\hline Rata-rata lebar sirkuit 6-8m & Rata-rata lebar sirkuit $6 \mathrm{~m}$ & \\
\hline $\begin{array}{l}\text { Rata-rata waktu } 1 \text { lap sekitar } 60 \\
\text { detik }\end{array}$ & $\begin{array}{l}\text { Rata-rata waktu } 1 \text { lap sekitar 22- } \\
50 \text { detik }\end{array}$ & $\begin{array}{l}\text { Disesuaikan dengan luas dan } \\
\text { bentuk site }\end{array}$ \\
\hline Jumlah gokar yang dapat & Jumlah gokar yang dapat & Disesuaikan dengan luas dan \\
\hline
\end{tabular}




\begin{tabular}{|c|c|c|}
\hline $\begin{array}{l}\text { digunakan pada waktu yang } \\
\text { bersamaan diatas } 24 \text { buah }\end{array}$ & $\begin{array}{l}\text { digunakan pada waktu yang } \\
\text { bersamaan adalah } 10-24 \text { buah }\end{array}$ & bentuk site \\
\hline $\begin{array}{l}\text { ( - ) Bisnis bergantung pada } \\
\text { cuaca } \\
\text { (+) Arena gokar yang biasa } \\
\text { digunakan oleh professional } \\
\text { ( + ) Memberikan pengalaman } \\
\text { maksimal terhadap gokar }\end{array}$ & $\begin{array}{l}(+) \text { Bisnis tidak bergantung pada } \\
\text { cuaca }(365 \text { hari/tahun }) \\
(+) \text { Sirkuit trek dapat diubah } \\
\text { dengan mudah }\end{array}$ & $\begin{array}{l}(+) \text { Menarik } \\
(+) \text { Baik untuk tempat yang } \\
\text { kecil } \\
(+) \text { Penggunaan tempat } \\
\text { dengan maksimal }\end{array}$ \\
\hline
\end{tabular}

Sumber: [3]

\subsection{RC Cars}

$R C$ Cars adalah suatu kegiatan yang mempergunakan sarana miniatur (model) mobil untuk tujuan rekreasi, edukasi, olahraga dan hobi. Kegiatan ini umumnya digemari anak-anak sampai orang dewasa, secara perorangan ataupun yang tergabung dalam komunitas sosial, yang digunakan untuk menyebarluaskan minat di bidang RC Cars [4].

a) RC Cars juga terdapat beberapa klasifikasi lagi atau jenis-jenis lainnya seperti: a) RC Cars on Road, adalah RC yang di aplikasikan pada sirkuit kering atau aspal.

b) RC Cars off Road, adalah RC yang diaplikasikan di sirkuit yang tidak halus seperti tanah dan bebatuan

\subsection{Utilitas Air Limbah}

Kegiatan usaha bengkel memiliki dampak positif dan dampak negatif. Dampak positifnya adalah memberi kontribusi bagi Pendapat Asli Daerah (PAD), memberikan kesejahteraan, serta memberikan kesempatan kerja. Sebaliknya, kegiatan usaha bengkel berpotensi menimbulkan persoalan lingkungan yang berupa kebisingan, pencemaran tanah, pencemaran air, pencemaran udara, ataupun gangguan kesehatan. Selain itu, persoalan lingkungan yang lebih serius dapat ditimbulkan oleh limbah bahan berbahaya dan beracun (B3) yang berupa oli bekas yang selanjutnya disebut minyak pelumas bekas sebagai akibat dari kegiatan usaha bengkel [5].

Karakteristik limbah bahan berbahaya dan beracun. Karakteristik limbah B3 meliputi :
a) Mudah meledak,
b) Mudah menyala,
c) Reaktif,
d) Infeksius,
e) Korosif,
f) beracun

Jenis limbah bahan berbahaya dan beracun. Jenis limbah B3 berdasarkan sumbernya meliputi:

a) Limbah B3 dari sumber tidak spesifik,

b) Limbah B3 dari kadaluwarsa, B3 yang tumpah, B3 yang tidak memenuhi spesifikasi produk yang akan dibuang, dan bekas kemasan,

c) Limbah B3 dari sumber spesifik.

Limbah B3 berdasarkan kategori bahayanya terdiri dari :

a) Limbah B3 kategori 1, dan

b) Limbah B3 kategori 2 .

Pengelolaan limbah bahan berbahaya dan beracun. Pengelolaan limbah B3 adalah kegiatan yang meliputi pengurangan, penyimpanan, pengumpulan, pengangkutan, pemanfaatan, pengolah-an dan/atau penimbunan. Dalam kegi-atan tersebut terdapat beberapa pihak yang masing-masing merupakan mata rantai dalam pengelolaan limbah B3, yaitu :
a) Penghasil limbah B3,
b) Pengumpul limbah B3,
c) Pengangkut limbah B3,
d) Pemanfaat limbah B3,
e) Pengolah limbah B3,
f) Penimbun limbah B3 


\subsection{Utilitas Pencahayaan Alami}

Pencahayaan alami dalam sebuah bangunan akan mengurangi penggunaan cahaya buatan, sehingga dapat menghemat konsumsi energi dan mengurangi tingkat polusi. Tujuan digunakannya pencahayaan alami yaitu untuk menghasilkan cahaya berkualitas yang efisien serta meminimalkan silau dan berlebihnya rasio tingkat terang. Selain itu cahaya alami dalam sebuah bangunan juga dapat memberikan suasana yang lebih menyenangkan dan membawa efek positif lainnya dalam psikologi manusia. Agar dapat menggunakan cahaya alami secara efektif, perlu dikenali ke sumber cahaya utama yang dapat dimanfaatkan : [6]:

1) Direct Sunlight, cahaya matahari langsung dan tingkat cahayanya tinggi.

2) Skylight, cahaya matahari yang sudah tersebar dilangit dan tingkat cahayanya rendah.

3) Reflected light, cahaya matahari yang sudah dipantulkan.

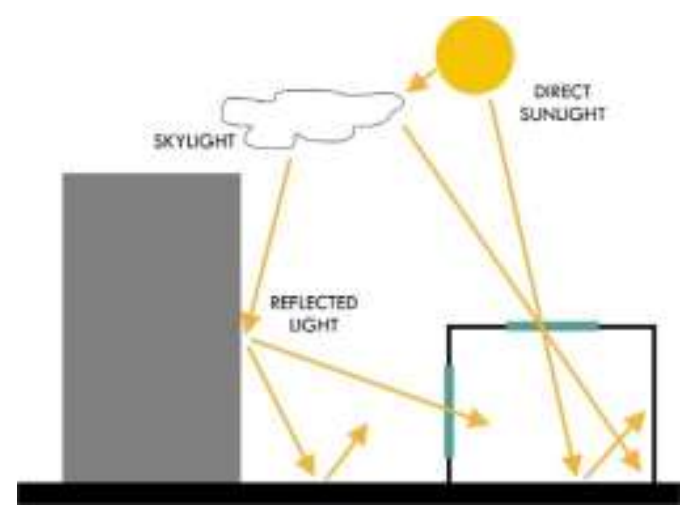

Gambar 2. Skema Pencahayaan Matahari

\subsection{Utilitas Penghawaan Alami}

Ventilasi bangunan dapat berupa ventilasi alami (tidak melibatkan mesin), ventilasi buatan (melibatkan mesin pengondisi udara yang akan menurunkan suhu dan kelembapan udara, AC dan ventilasi semi buatan (ventilasi alami yang dibantu oleh kipas angin untuk menggerakkan udara tetapi tidak melibatkan alat penurun suhu). Ventilasi dibutuhkan agar udara di dalam ruangan tetap sehat dan nyaman. Baik aktivitas manusia maupun benda-benda di dalam ruang dapat menghasilkan gas-gas yang berbahaya bagi kesehatan bila tetap terkonsentrasi di dalam jumlah yang melebihi batas toleransi manusia. Udara yang kotor harus diganti dengan udara yang lebih bersih [7].

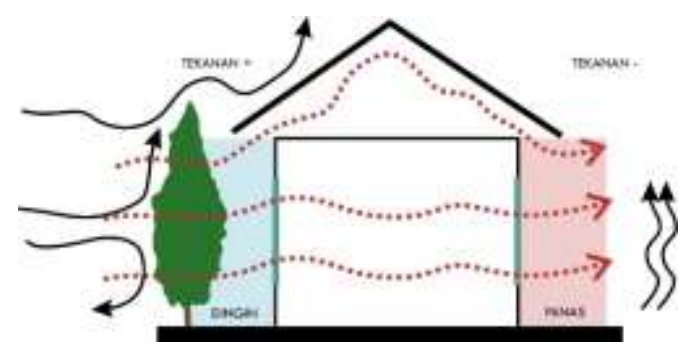

Gambar 3. Skema Penghawaan Alami

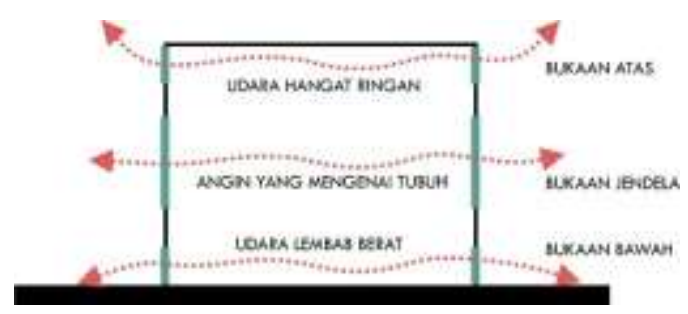

Gambar 4. Skema Bukaan Pada Bangunan 


\subsection{Gaya Arsitektur Industrial}

Pada Arsitektur Industrial, bentuk bangunan sangat mengedepankan aspek fungsional bangunan, maka bentuk dasar yang digunakan adalah gabungan antara bujur sangkar dan segitiga. Bentuk tersebut memiliki garis tegas dan dinamis dengan menambah unsur penggabungan, penambahan atau pengurangan maupun pengolahan dengan garis-garis vertikal-horizontal, silang tegak lurus, silang miring, permainan bidang, maupun permainan bentuk.

Menurut Lloyd [8], faktor konstruksi dalam sebuah ruang kreatif yang harus diterapkan adalah langitlangit yang tinggi untuk menciptakan keterbukaan dalam berkomunikasi dan kebebasan bergerak penggunanya. Jika langit-langit tinggi, maka akan memunculkan ide akan kebebasan, tanpa Batasan. Langit-langit pada bangunan industri tidak ditutup plafon. Saluran pipa air, listrik, pemanas, ventilasi, dan pendingin udara dibiarkan terekspos. Selain membuat ruangan terasa lebih tinggi dan luas, langit-langit terbuka juga mampu memotong biaya untuk pemasangan plafon menjadi lebih efisien.

\section{Metode Perancangan}

Untuk memulai perancangan sebuah Arena Gokar dan RC Cars Indoor di Pulau Kumala Tenggarong menggunakan metode kualitatif dan destriktif dari hasil perancangan.

Tahapan-tahapan perencanaan yang dilaksanakan dalam menyelesaikan tugas akhir dengan judul "Perencanaan Arena Gokar dan RC Cars Indoor di Pulau Kumala Tenggarong adalah: Identifikasi Masalah, Pengumpulan Data, Analisis Data, Konsep dan Perancangan.

Adapun Langkah-langkah dalam metode pengolahan data adalah sebagai berikut :

a) Membuat analisis perancangan arena gokar dan RC Cars, meliputi: program ruang, analisis aktivitas, analisis kebutuhan dan besaran ruang,

b) Analisis Tapak pada site terpilih yaitu di Pulau Kumala Tenggarong. Analisis ini meliputi, analisis ondisi site, Analisis matahari dan kebisingan, Analisis Pencapaian dan sirkulasi tapak, serta analisis view.

c) Analisis Bangunan yaitu Analisis gubahan massa dan analisis Gaya Bangunan Industrialis.

d) Analisis Utilitas yang terdiri dari utilitas limbah, utilitas pencahayaan alami dan utilitas penghawaan alami.

e) Membuat konsep perancangan, meliputi : Konsep Peruangan, Konsep Utilitas dan Konsep Gaya Bangunan

\section{Hasil dan Pembahasan}

Berdasarkan hasil perencanaan dan pembahasan dapat disimpulkan bahwa Perencanaan Arena Gokar dan RC Cars Indoor di Pulau Kumala Tenggarong merupakan suatu cara untuk menghadirkan fasilitas hiburan dan permainan yang baru di Pulau Kumala Tenggarong.

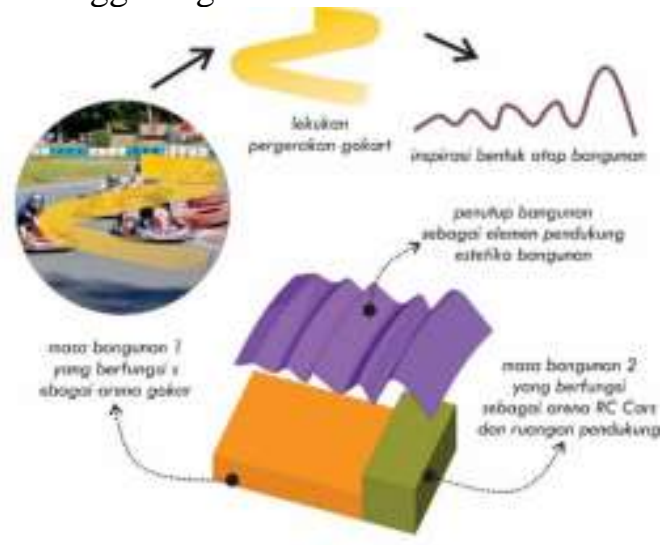

Gambar 5. Gubahan Massa

Gubahan massa pada bangunan Arena Gokar dan RC Cars Indoor ini berawal dari bentuk empat kotak sederhana yang disatukan, lalu diberi atap yang berbentuk gelombang, yang terinsipirasi dari lekukan dari manuver gokar saat sedang balapan. 


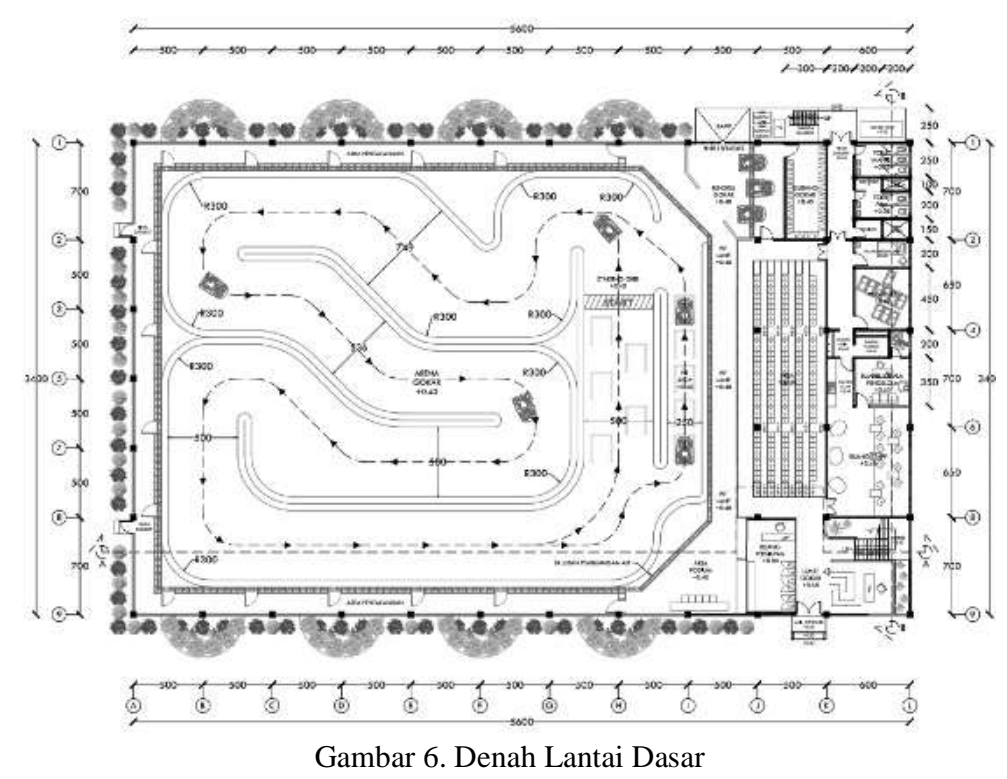

Pada denah lantai dasar terdapat loket gokar, ruang persiapan, tribun, arena gokar, ruang staf, ruang kepala pengelola, musholla, ruang kesehatan, area wudhu, pantry staf, toilet, gudang gokar, dan bengkel gokar

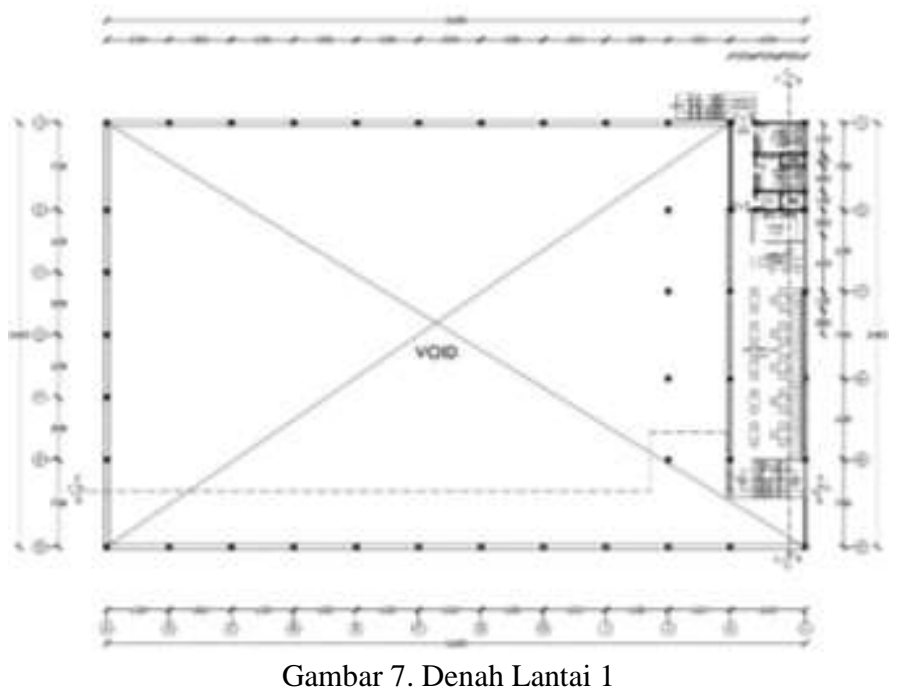

Pada denah lantai 1 terdapat mini café yang terdiri dari area makan, minibar, dapur, toilet dan janitor, terdapat void yang lebar agar pengunjung dapat menikmati pertunjukan balap gokar sekaligus bersantai di minicafe 


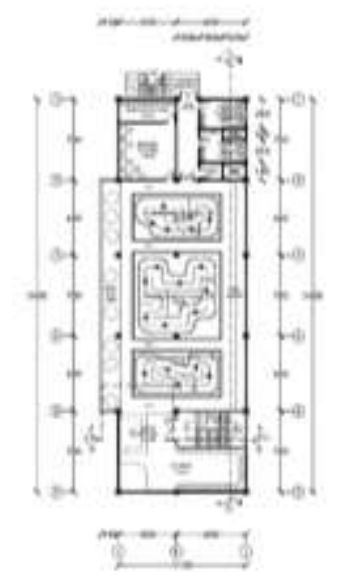

Gambar 8. Denah Lantai 2

Pada denah lantai 2 terdapat loket RC Cars, RC Shop, arena RC Cars, bengkel RC Cars, toilet dan janitor.

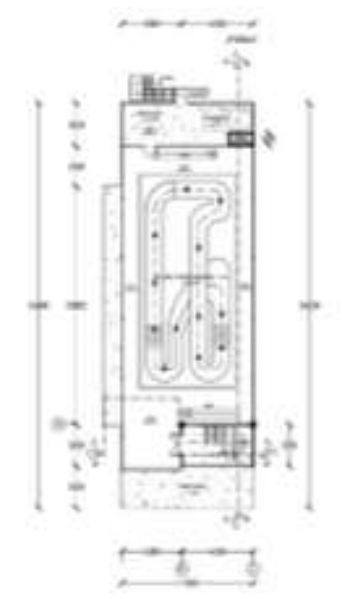

Gambar 9. Denah Lantai Atap

Pada denah lantai atap terdapat arena RC Cars Outdoor dan area utilitas untuk meletakkan tandon.

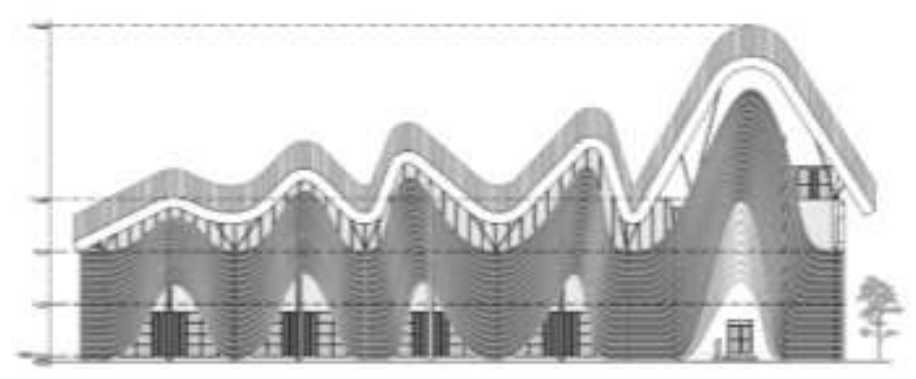

Gambar 10. Tampak Depan

Tampak depan bangunan menampilkan secondary skin yang terbuat dari material besi dengan bentukan gelombang yang terinspirasi dari manuver gokar, secondary skin pada fasad menjadikan vocal point pada bangunan ini. 


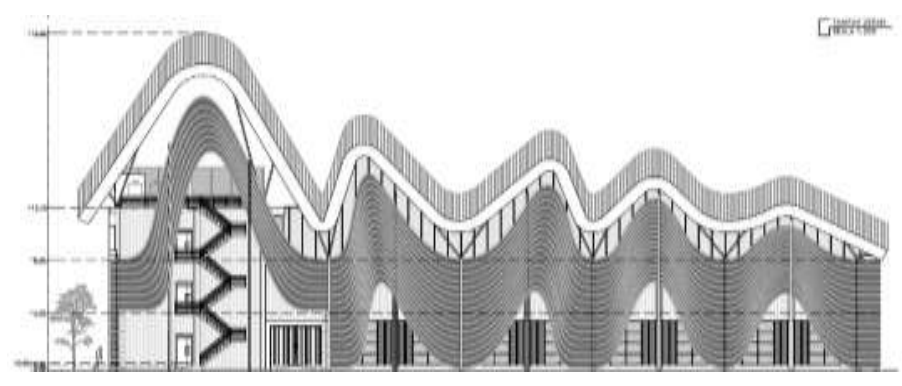

Gambar 11. Tampak Belakang

Tampak belakang bangunan tetap menampilkan secondary skin sebagai vocal point pada bangunan, namun terdapat pengurangan secondary skin pada area tangga darurat agar sirkulasi dari tangga darurat dapat terlihat dari luar bangunan.

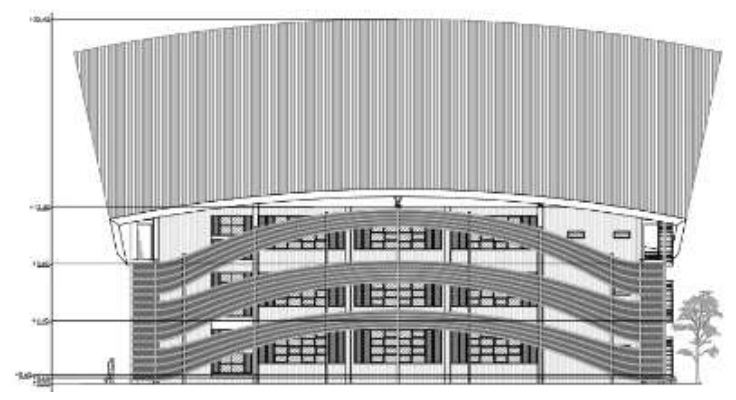

Gambar 12. Tampak Samping Kanan

Tampak samping kanan bangunan terlihat material pelapis dinding yang berasal dari atap zincalume serta tetap menampilkan secondary skin sebagai vocal point pada bangunan, juga terdapat pengurangan secondary skin pada area jendela-jendela, agar cahaya matahari dan udara alami dapat mudah masuk kedalam bangunan.

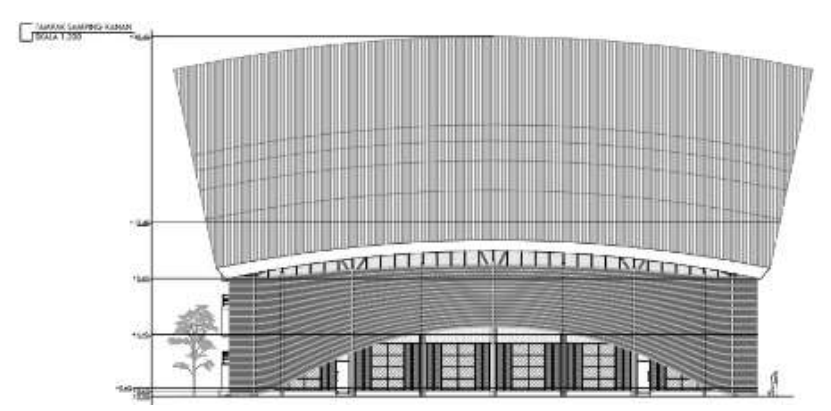

Gambar 13. Tampak Samping Kiri

Tampak samping kiri bangunan terlihat material pelapis dinding yang berasal dari atap zincalume, juga tetap menampilkan secondary skin sebagai vocal point pada bangunan,

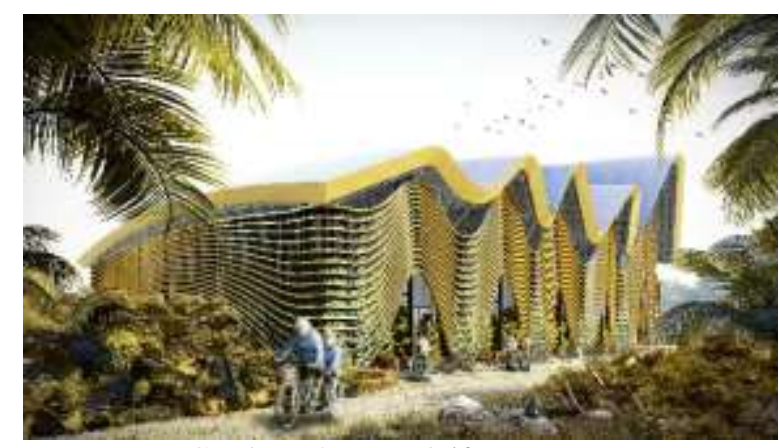

Gambar 14. Perspektif Bangunan 
Perspektif dari bangunan Arena Gokar dan RC Cars Indoor yang menggunakan gaya industrial, terlihat pada penggunaan material besi pada secondary skin, kolom cor beton ekspos, pelapis dinding atap zincalume. dan atap gelombang sebagai vocal point pada keseluruhan bangunan. bangunan akan telihat seperti memiliki skala monumental karena ukuran bangunan yang tinggi serta memiliki gubahan massa yang masif/padat, sehingga untuk mengurangi kesan monumental tersebut diletakkan secondary skin yang memilki bentuk gelombang dengan arah horizontal yang dapat mengurangi kesan monumental pada bangunan.

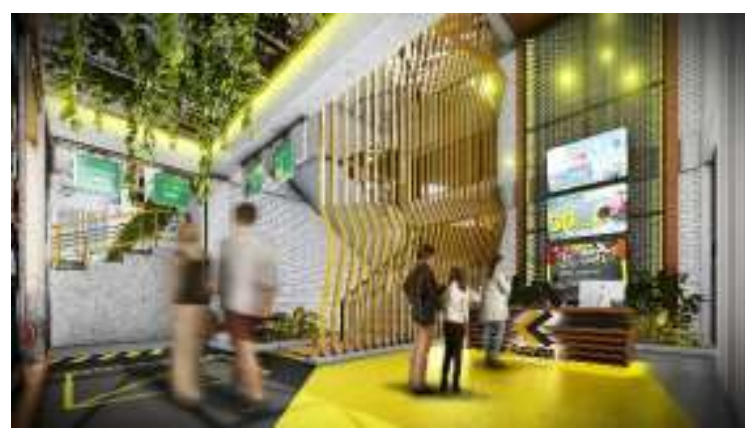

Gambar 16. Perspektif Interior Lobby

Perspektif interior dari ruangan lobby yang menggunakan gaya industrial terlihat pada penerapan furniture dan dekorasi yang terbuat dari material beton ekspos, besi yang di finishing cat, lantai ekspos yang di cat, serta material kayu dan tanaman rambat untuk memberi kesan hangat pada ruangan.

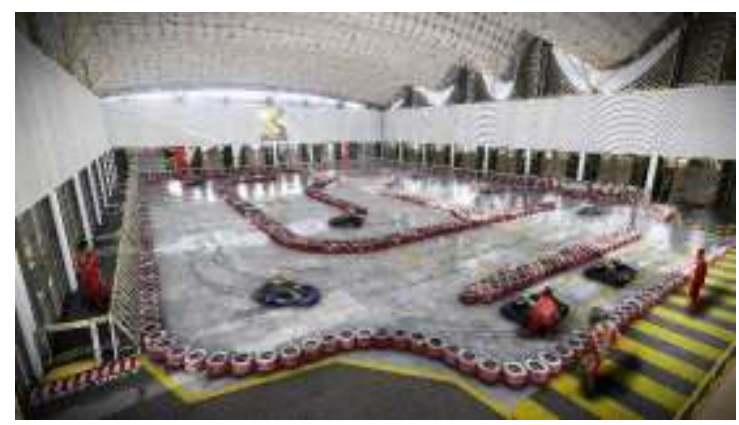

Gambar 17. Perspektif Interior Arena Gokar

Perspektif interior dari ruangan arena gokar yang menggunakan gaya industrial, lantai dari arena tersebut menggunakan cor beton ekspos yang di polish agar tidak kasar, menggunakan ban-ban bekas yang diperbarui sehingga menjadi menarik. Material zincalume pada dinding and Atap spaceframe yang diekspos juga menambah suasana industrial pada ruangan.

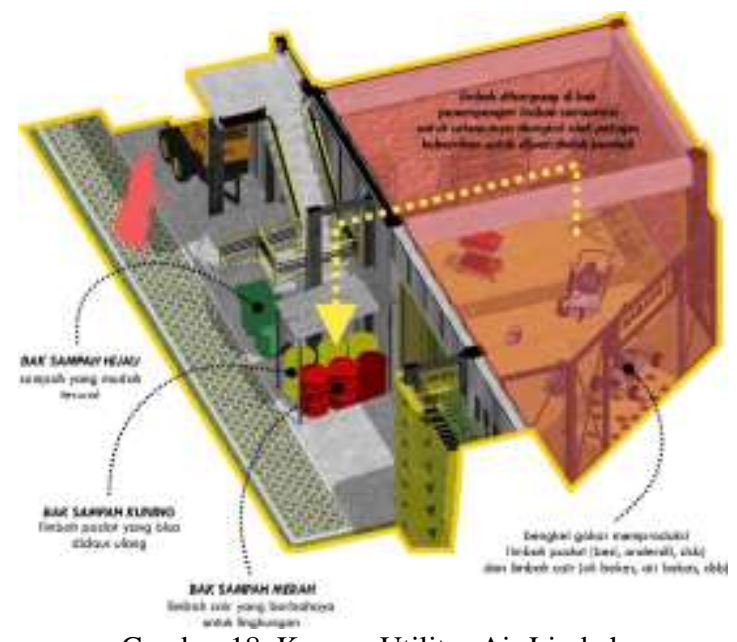

Gambar 18. Konsep Utilitas Air Limbah 
Bengkel gokar yang memproduksi limbah seperti limbah padat dan limbah cair harus diperhatikan jalur pembuangannya, dengan cara membuat penampungan sementara limbah pada bagian belakang bangunan/area service, area penampungan memiliki bak-bak yang terdiri dari :

- Bak sampah hijau, bak untuk sampah-sampah yang mudah terurai seperti makanan

- Bak sampah kuning, bak untuk limbah padat yang akan didaur ulang seperti potongan besi, rangka besi

- Bak sampah merah, bak untuk limbah cair yang akan dijual seperti oli bekas.

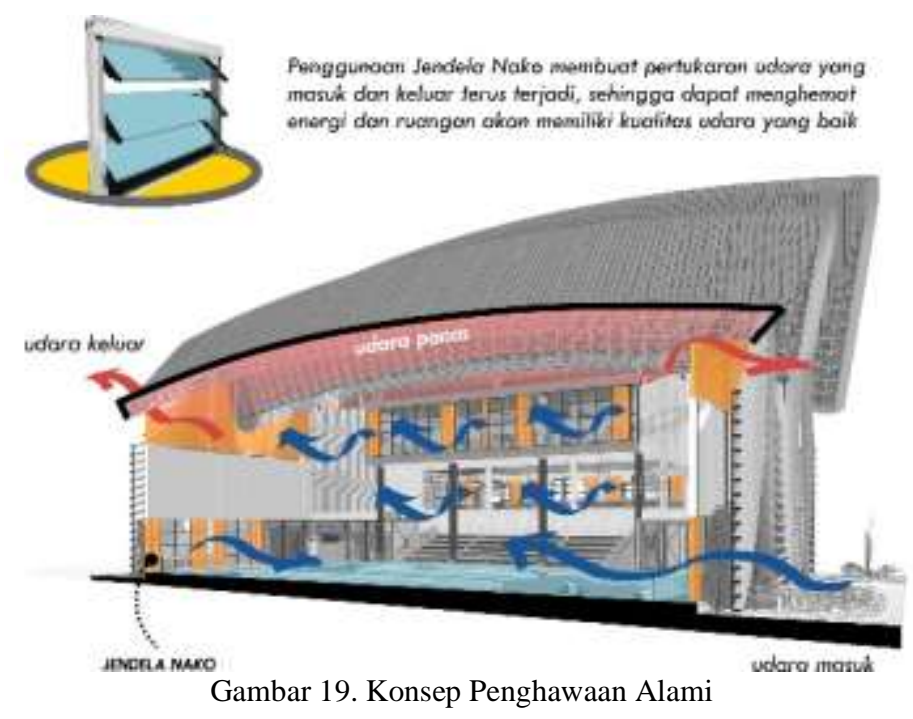

Arena gokar membutuhkan sirkulasi udara dengan baik agar kegiatan dapat berjalan dengan nyaman, maka dari itu diterapkan konsep penghawaan alami menggunakan jendela nako, jendela nako dapat membuat sirkulasi udara terus terjadi sehingga udara yang masuk ke dalam bangunan memiliki kualitas yang baik. Penerapan jendela nako tidak hanya di arena gokar, namun disetiap ruangan yang dirasa perlu untuk dimasukkan udara alami seperti ruang staff, lobby, minicafe, arena RC Cars Indoor dan toilet.

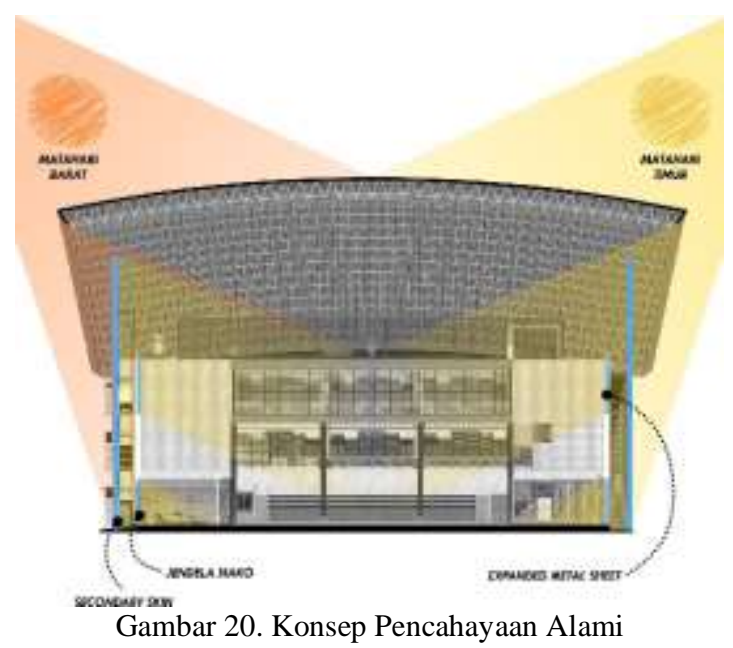

Selain membutuhkan peng-hawaan alami, bangunan Arena Gokar dan RC Cars Indoor ini membutuhkan pencahayaan alami, karena jenis kegiatan yang mendukung untuk memasukkan cahaya alami seperti balap gokar, maka dari itu diterapkan banyak bukaan disekitar bangunan khususnya pada arena gokar, bukaan tersebut berupa kaca mati yang dikombinasikan dengan jendela nako, agar tidak terlalu banyak memasukkan cahaya matahari yang dapat menyebabkan pembalap gokar silau, maka diletakkan secondary skin disekeliling bangunan, serta overstek dari atap yang dapat mengurangi intensitas cahaya matahari yg masuk. Setiap ruangan terdapat jendela yang dapat memasukkan intensitas cahaya matahari sesuai keperluan. Konsep pencahayaan alami ini dapat membuat bangunan lebih hemat energi karena tidak perlu menyalakan lampu pada siang hari. 


\section{Kesimpulan Dan Saran Kesimpulan}

Berdasarkan hasil observasi dan survey pada arena gokar di Pulau Kumala Tenggarong yang dalam kondisi sudah tidak terawatt dan mengalami beberapa kerusakan di bangunannya.

Dalam mendesain Arena Gokar dan RC Cars Indoor menggunakan gaya Industrial yang cocok dengan tema olahraga gokar. Dalam desain Arena Gokar dan RC Cars Indoor juga memperhatikan sistem pencahayaan alami, penghawaan alami dan penampungan limbah bengkel, hal ini bertujuan agar mengurangi penggunaan energi listrik, membuat sirkulasi udara dalam bangunan tetap nyaman, dan hasil limbah tidak mencemari lingkungan yang berada disekitar bangunan.

\section{Saran}

Adapun saran yang penulis dapat sampaikan, yaitu :

Dalam merencanakan sebuah Arena Gokar dan RC Cars Indoor sebaiknya memperhatikan standar-standar ukuran atau dimensi ruang agar pengguna bangunan dapat merasakan kenyaman dan keamanan dalam melakukan aktifitas didalam bangunan, menampilkan gaya bangunan industrial yang dapat mendukung suasana dari tema permainan itu sendiri (gokar), menerapkan sistem pencahayaan alami, penghawaan alami agar mengurangi penggunaan energi listrik dan memperhatikan limbah yang dihasilkan pada bangunan 
Mafazah Noviana, Cisyulia Octavia, Rahmat Dwi Saputra Perencanaan Arena Gokar dan RC Cars Indoor di Pulau Kumala Tenggarong Penekanan Pada Utilitas

\section{Daftar pustaka}

1. Daryanto, Teknik Merawat Automobil Lengkap. Bandung: CV. Yrama Widya. 2002, Bandung: CV Yrama Widya.

2. Suratman, M., Servis Dan Teknik Reparasi Sepeda Motor. Bandung: PT. Pustaka Grafika. 2002, Bandung: PT. Pustaka Grafika.

3. Adisumarto, Henson, and S.P. Honggowidjaja, Perancangan Interior Café Go Kart di Surabaya. JURNAL INTRA, 2017. 5: p. 10 .

4. Pamingkas and Adriansyah, Perancangan Pusat Mainan Remote Control di Tangerang Selatan, in Structural Expressionism. 2017, Jurusan Teknik Arsitektur UIN: Malang.

5. Yeni, A.A.B., 2015.

6. Sistem Pencahayaan alami. 23 Februari 2020. https://www.kajianpustaka.com/23/12/sistem-pencahayaanalami.html. Kajian Pustaka 2013 [cited 202023 Februari 2020]; Available from:

https://www.kajianpustaka.com/23/12/sistem-pencahayaan-alami.html.

7. $\quad$ Satwiko, P., Fisika Bangunan. 2009, Yogyakarta: Andi.

8. Lloyd, P. Creative Space. 2009; Available from: www.catalystr-anchmeetings.com/ThinkingDocs/Crative-Spaceby-Peter-Lloyd.pdf. 